\title{
New species of Kiluluma Skrjabin, 1916 (Nematoda: Strongylida) from the white rhinoceros Ceratotherium simium (Burchell), with a redescription of $K$. solitaria Thapar, 1924
}

\section{Ian Beveridge • Abdul Jabbar}

Received: 26 January 2013 / Accepted 15 March 2013

\section{Beveridge $(\bowtie) \cdot$ A. Jabbar}

Department of Veterinary Science, University of Melbourne, Veterinary Clinical Centre, Werribee, Victoria 3030, Australia

e-mail: $\underline{\text { ibeve@unimelb.edu.au }}$

\begin{abstract}
Three species of Kiluluma Skrjabin, 1916 were identified in Ceratotherium simium (Burchell) from a captive population in New South Wales, Australia, based on analysis of the second internal transcribed spacer (ITS-2) of ribosomal DNA. One species was identified as $K$. solitaria Thapar, 1924 and is redescribed. A second species is new and is described here as $K$. ceratotherii $\mathrm{n}$. sp. The third species is new but was represented by two individuals only and is described but is not named.
\end{abstract}

\section{Introduction}

Kiluluma Skrjabin, 1916 was erected for Deletrocephalus stylosus Linstow, 1907, a nematode described from a black rhinoceros, Diceros bicornis (Linnaeus), as the morphological characteristics of the species differed markedly from those of the type-species $D$. dimidiatus Diesing, 1851 found in rheas. Thapar $(1924,1925)$ described ten new species (K. rhinocerotis Thapar, 1924, K. africana Thapar, 1924, K. pachyderma Thapar, 1924, K. macdonaldi Thapar, 1924, K. solitaria Thapar, 1924, K. magna Thapar, 1924, K. goodeyi Thapar, 1925, K. brevicauda Thapar, 1925, K. 
brevivaginata Thapar, 1925, K. cylindrica Thapar, 1925) from D. bicornis from Uganda and "East Africa", but effectively ignored the description of $K$. stylosa, as he considered it to be inadequate for the recognition of this species. Taylor (1925) working on collections of nematodes from rhinoceroses held at the Liverpool School of Tropical Medicine considered that the descriptions of Thapar (1924) were inadequate and suggested that K. rhinocerotis, K. africana, K. pachyderma and K. solitaria were synonyms. By contrast, Mönnig (1927) examining specimens held in the collections of the Onderstepoort Institute of Veterinary Research was able to identify each of these species and described a new species, K. longispiculata Mönnig, 1927, which proved to be a synonym of $K$. goodeyi. Sandground (1933) in describing K. vernayi from the Javan rhinoceros, Rhinoceros sondaicus Desmarest, was also highly critical of Thapar's descriptions. Consequently, there are 12 potentially valid species within the genus, $K$. stylosa and the 10 species described by Thapar $(1924,1925)$ from African rhinoceroses and $K$. vernayi from the Javan rhinoceros.

Subsequent reviews of the parasites of rhinoceroses (Round, 1968; Jooste, 1990; Penzhorn et al., 1994) have summarized previous geographical records, with Jooste (1990) adding the white rhinoceros, Ceratotherium simium (Burchell), as a host of $K$. cylindrica, K. goodeyi and $K$. rhinocerotis. Knapp et al. (1997) studied new collections of helminths from both black and white rhinoceroses in southern Africa and identified $K$. goodeyi and K. magna in black rhinoceroses and $K$. rhinocerotis in the white rhinoceros. The remaining specimens of Kiluluma they were unable to identify with certainty and suggested that a combined morphological and molecular approach would be needed to establish the validity of species within this genus.

The opportunistic collection of nematodes from white rhinoceroses dying at a zoo in New South Wales, Australia, has allowed such an approach in which DNA (second internal transcribed spacer, ITS-2) data and morphological data were available for the same specimens. On this basis, we here redescribe $K$. solitaria and describe two new species.

\section{Materials and methods}

Nematodes were obtained from two white rhinoceroses, Ceratotherium simium (Burchell), which died from unknown causes at Western Plains Open Range Zoo, Dubbo, New South Wales, Australia. Nematodes recovered at autopsy were preserved in $70 \%$ ethanol. The mid-section of the body was removed from 24 nematodes for molecular analyses and the anterior and posterior extremities were cleared in lactophenol for morphological examination. Six nematodes were 
retained intact for morphological examination only. Nematodes were examined initially using molecular methods. Different genotypes based on differences in the second internal transcribed spacer regions (ITS-2) of ribosomal DNA were then examined morphologically.

\section{Molecular methods}

The mid body portion of each nematode $(n=24)$ was used for DNA isolation. Prior to DNA extraction, the ethanol was removed by washing each worm individually three times (45 min) in $\mathrm{H}_{2} \mathrm{O}$, and then suspended in $\sim 200 \mu \mathrm{l}$ of $20 \mathrm{mM}$ Tris- $\mathrm{HCl}$ (pH 8.0), $100 \mathrm{mM}$ EDTA, $1 \%$ sodium dodecyl-sulphate (SDS) containing $10 \mathrm{mg} / \mathrm{ml}$ proteinase K (Amresco Inc., Solon, Ohio, USA) and incubated at $37^{\circ} \mathrm{C}$ for $\sim 18 \mathrm{~h}$. Total genomic DNA was isolated from the homogenised suspension using a mini-column (Wizard ${ }^{\circledR}$ DNA Clean-Up System, Promega, Wisconsin, USA), according to the manufacturer's protocol.

The ITS-2 (including flanking sequence) was amplified by PCR from the gDNA (10-20 ng template) of individual nematodes using primers NC1 (5' -ACG TCT GGT TCA GGG TTG TT$3^{\prime}$ ) and NC2 (5' -TTA GTT TCT TTT CCT CCG CT-3' ) (Gasser, 2006). PCRs were conducted in $50 \mu \mathrm{L}$ volumes containing $10 \mathrm{mM}$ Tris- $\mathrm{HCl}$ (pH 8.4), $50 \mathrm{mM} \mathrm{KCl}$ (Promega), $3.5 \mathrm{mM} \mathrm{MgCl}_{2}$, $200 \mathrm{M}$ of each deoxynucleotide triphosphate (dNTP), 50 pmol of each primer and 1U of GoTaq polymerase (Promega). The PCR conditions used were: $94^{\circ} \mathrm{C}$ for $5 \mathrm{~min}$, then 35 cycles of $94^{\circ} \mathrm{C}$ for $30 \mathrm{~s}, 55^{\circ} \mathrm{C}$ for $30 \mathrm{~s}$ and $72^{\circ} \mathrm{C}$ for $30 \mathrm{~s}$, followed by $72^{\circ} \mathrm{C}$ for $10 \mathrm{~min}$. Negative (no-DNA) and known positive [Haemonchus contortus (Rudolphi, 1802)] controls were included in each set of PCRs.

Amplicons were subjected to $1.5 \%$ agarose gel electrophoresis, and photographed upon transillumination using a GelDoc system.

The ITS-2 amplicons from 24 nematodes were subjected to SSCP analysis using protocol B of Gasser et al. (2006) to screen for sequence variation among individual worms. One to five amplicons representing each unique SSCP profile were treated using two enzymes, shrimp alkaline phosphatase and exonuclease I (Fermentas Inc. Glen Burnie, MD, USA), as described previously (Werle et al., 1994) and subjected to automated DNA sequencing (BigDye ${ }^{\circledR}$ Terminator v.3.1 chemistry, Applied Biosystems, Foster City, CA, USA) using primers NC1 and NC2 in separate reactions. The quality of each sequence was assessed by appraising the corresponding electropherogram using the program BioEdit (Hall, 1999).

The consensus ITS-2 sequences of Kiluluma spp. determined herein were aligned (over 277 bp length) with the sequences for Strongylus vulgaris (Looss, 1900), Murshidia africana Lane, 1921 and Trichostrongylus axei (Cobbold, 1879), which were used as outgroups (Campbell et al., 1995; 
Hoste et al., 1995; McLean et al., 2012). The analysis of sequence data was conducted using Bayesian inference (BI), employing the Monte Carlo Markov Chain (MCMC) method of MrBayes 3.1.2 (Huelsenbeck \& Ronquist, 2001; Ronquist \& Huelsenbeck, 2003). The likelihood parameters were set based on the Akaike Information Criteria (AIC) test in Modeltest v3.7 (Posada \& Crandall, 1998). The general time-reversible model of evolution, with gamma-distribution and a proportion of invariable sites $(\mathrm{GTR}+\Gamma+\mathrm{I})$, was utilised for the analysis of the ITS-2 sequence data. Posterior probabilities (pp) were calculated for 2,000,000 generations, utilising four simultaneous treebuilding chains, with every 100th tree being saved. At this point, the potential scale reduction factor approached one, and the standard deviation of split frequencies was $<0.01$. A consensus tree $(50 \%$ majority rule) was constructed based on the final $75 \%$ of trees generated.

\section{Morphological methods}

Nematodes were measured under a compound microscope using an ocular micrometer. Drawings were made with a drawing tube attached to an Olympus BH microscope. Measurements are presented in millimetres as the mean followed by the range and the numbers of measurements made in parentheses. As most specimens were used for molecular analyses, there are few measurements of total lengths. Drawings are oriented with the dorsal aspect of each illustration towards the top of the page. In the descriptions of the bursal rays, both the descriptive system of Yorke \& Maplestone (1926) and the numerical system of Chabaud et al. (1970) are used.

Specimens have been deposited in the Natural History Museum, London (BMNH) and the collection of the Onderstepoort Veterinary Research Institute, Pretoria (OVRI). Specimens described here were compared with the type-specimens of $K$. rhinocerotis (BMNH 1998.11.20.167186), K. africana (BMNH 1998.11.20.1-10), K. pachyderma (BMNH 1998.11.20.117-166), K. macdonaldi (BMNH 1998.11.20.57-76) and K. solitaria (BMNH 1998.11.20.187-188) as well as specimens identified as K. stylosa from the collection of Prof. W. Yorke from Zimbabwe (Rhodesia) (BMNH 1925.4.22.9-88).

\section{Results}

DNA was extracted from each of 24 nematodes and subjected to PCR-based SSCP analysis of the ITS-2. No variation in size (approximately $325 \mathrm{bp}$ ) was detectable on agarose gels among the ITS-2 amplicons of the rhinoceros nematodes. Based on SSCP analysis of amplicons from each isolate, 
three different SSCP profiles were recorded. Aliquots of the amplicons representing the three profiles were subjected to sequencing, and three distinct the ITS-2 sequences (GenBank accession numbers JX982335-JX982337) were obtained. Sequencing of the ITS-2 rDNA (i.e. excluding the $\sim 50 \mathrm{bp}$ of the flanking regions) yielded sequences of $277 \mathrm{bp}$, which were compared over an alignment length of 278 characters. Sequence variation among the individual nematodes varied from 0 to $5.8 \%$. Pairwise comparisons among three genotypes revealed sequence variation ranging from 4.0 to $5.8 \%$.

Phylogenetic analysis (Fig. 1) indicated that the sequences of Kiluluma spp. formed a single clade with each sequence type exhibiting reciprocal monophyly. The ITS-2 sequence data corresponded with three morphologically distinct groups of nematodes which are described below.

\section{Kiluluma solitaria Thapar, 1924}

Material examined: 2 ๙ิึ, 3 $\uparrow$, from large intestine of Ceratotherium simium, Western Plains Open Range Zoo, Dubbo, New South Wales, Australia.

Deposition of specimens: BMNH 2012.11.14.1-5.

Deposition of DNA data: Genotype 2; GenBank accession No. JX982337.

\section{Redescription (Figs. 2-13)}

General. Body with prominent, widely-spaced annulations; numerous very fine annulations between more prominent annulations; cervical cuticle inflated; cephalic collar prominent; mouth opening surrounded by 6 prominent lips, 2 lateral amphids, 4 submedian bipartite papillae surmounted on conical elevations of cuticle. Internal leaf crown of 6 elements with recurved tips associated with each lip; tips of leaf crown elements projecting beyond lips. Buccal capsule thick-walled, circular in apical view, prominently lobed anteriorly in dorsal-ventral and lateral views. Oesophagus clavate, with 3 small teeth in oesophageal funnel; denticles present in lumen of oesophagus near anterior extremity. Nerve-ring in mid-region of oesophagus; deirids and excretory pore posterior to oesophagus. 
Male. Total length not obtained; maximum width $0.52-0.54(0.53, \mathrm{n}=2)$; buccal capsule 0.07 wide $(n=2) \times 0.02$ deep $(n=2)$; oesophagus $0.32-0.40(0.36, n=2)$ long; nerve-ring 0.17-0.18 $(0.18, n=2)$, excretory pore $0.57-0.69(0.63, \mathrm{n}=2)$ and deirids $0.61-0.74(0.68, \mathrm{n}=2)$ from anterior end. Bursa without clear distinctions between ventral, lateral and dorsal lobes; dorsal lobe slightly longer than other lobes; pre-bursal ray (1) short, stout; ventro-ventral (2) and ventro-lateral (3) rays apposed, reaching margin of bursa; antero-lateral (4) and medio-lateral (5) rays apposed, reaching margin of bursa; postero-lateral ray (6) divergent from other lateral rays, not reaching margin of bursa; externo-lateral ray (8) arising from lateral trunk, reaching margin of bursa; dorsal ray broad at origin, lateral branches arising close to origin, short, each with 2 papillae; main trunk of dorsal ray elongate, dividing near extremity into two short branchlets each with single papilla. Genital cone with large ventral projection bearing single terminal papilla (0); dorsal lip with paired conical projections (7) each bearing single terminal papilla; dorsal lobe of cone surrounded by array of projections. Spicules elongate alate; major ala arising immediately posterior to capitulum of spicule and extending almost to distal tip of spicule; spicules sinuous, ala arranged spirally around spicule; in distal region, smaller ala present on opposite side of spicule; spicule tips blunt; spicules 1.68-1.98 (1.82, n=3) long; gubernaculum sub-cordiform, 0.09 long.

Female. Length 14.3-15.2 (14.8, n=2), maximum width 0.49-0.55 (0.52, n=3); buccal capsule 0.065-0.070 (0.068, n=3) wide $\times 0.015-0.025(0.020, \mathrm{n}=3)$ deep; oesophagus $0.40-0.46(0.43)$ long; nerve-ring $0.18-0.23(0.1, \mathrm{n}=3)$, excretory pore $0.65-0.73(0.69)$ and deirids $0.71-0.77(0.73$, $\mathrm{n}=3)$ from anterior end; tail short, conical, $0.16-0.19(0.18, \mathrm{n}=3)$ long; vulva immediately anterior to anus, $0.22-0.26$ from posterior end; vagina vera 1.26-1.30 (1.28, $\mathrm{n}=3)$ long; sphincters and infundibula not differentiable, 1.60-1.75 (1.68, n=3) long; eggs thin-shelled ellipsoidal, $0.09(\mathrm{n}=3) \times$ $0.05(n=3)$.

\section{Remarks}

The specimens described here are distinguished from K. brevicauda, K. brevivaginata, K. goodeyi and $K$. vernayi all of which have eight rather than six leaf crown elements. In addition, the spicules of these species range from 4.9-9.5 mm long compared with 1.68-1.98 $\mathrm{mm}$ in the current specimens. Kiluluma magna was excluded from consideration as the excretory pore and deirids are in the mid-oesophageal region rather than posterior to the oesophagus in remaining congeners. The 
dorsal ray of $K$. cylindrica has the lateral branches arising at mid-length and extending as far as the terminal branches; it therefore differs significantly from the species described here and is not considered further. The current specimens were therefore compared with the type-series of $K$. rhinocerotis, $K$. africana, K. pachyderma, K. macdonaldi and $K$. solitaria, all of which have spicule lengths in the range $1.9-2.6 \mathrm{~mm}$. The types are in a poor state of preservation [in contradiction to the assessment of Thapar (1924) although their condition may have deteriorated since his study] and it is difficult to discern many internal features. In addition some specimens identified as K. stylosa from the collection of Prof. Yorke were examined. The current specimens resemble K. solitaria in having a lobed anterior margin to the buccal capsule and in having numerous projections around the genital cone. Thapar $(1924,1925)$ illustrated a lobed buccal capsule only in K. solitaria but did not mention it in his description, even though this character appears to differentiate it from all congeners. The projections around the genital cone again were not mentioned in the description but are clearly visible in the holotype and were not seen in males of the other species. In addition, $K$. pachyderma and $K$. macdonaldi do not have the prominently projecting lips, while the specimens identified as $K$. stylosa also lack lips and have very prominent leaf crown tips, as illustrated by Skrjabin (1916) and reproduced by Neveu-Lemaire (1924) as well as a much broader oesophagus.

The dorsal rays of each of the five species were also compared based on type-specimens (Figs. 37-41) and there are some differences in the lengths of the lateral branchlets of $K$. macdonaldi and K. pachyderma in particular which help to distinguish these species. Due to the state of preservation of the specimens, the number of papillae on the lateral branchlets of the dorsal ray could not be determined in every species. $K$. rhinocerotis and $K$. africana are also readily differentiable as they have relatively deeper buccal capsules and the tips of the leaf crown elements do not project. The only feature of the current redescription which does not match the original is the relative size of parts of the female genital system. In Thapar's (1924) description of K. solitaria, the vagina vera is longer than the sphincters and infundibula, whereas in the case of the current specimens the infundibula and sphincters are slightly longer than the vagina although the latter measurements vary considerably and more specimens are required to establish the extent of variation in these characters. Consequently, the specimens described here are considered to belong to $K$. solitaria, although new detailed descriptions based on well-preserved specimens are needed for most species of the genus. 
Kiluluma ceratotherii $\mathrm{n}$. sp.

\section{Type-host: Ceratotherium simium.}

Type-locality: Western Plains Zoo, Dubbo, New South Wales, Australia.

Site in host: Large intestine.

Type-specimens: holotype BMNH 2012.11.14.6; allotype BMNH 2012.11.14.7; paratypes, 5 ふð, 5

$q$,, BMNH 2012.11.14.8-17, 5 ふ઼, 5 우, OVRI, National Collection of Animal Helminths 1.1-10. Etymology: The new species is named after the host.

Deposition of DNA data: Genotype 1, GenBank accession No. JX982335.

\section{Description (Figs. 14-25)}

General. Body with prominent widely-spaced annulations; numerous very fine annulations between more prominent annulations; cervical cuticle inflated; cephalic collar prominent; mouth opening surrounded by 6 prominent lips, 2 lateral amphids, 4 submedian bipartite papillae surmounted on conical elevations of cuticle. Internal leaf crown of 6 elements with recurved tips associated with each lip; tips of leaf crown elements project beyond lips. Buccal capsule thick-walled, circular in apical view, prominently lobed anteriorly in dorsal-ventral and lateral views. Oesophagus clavate, without teeth in oesophageal funnel; denticles present in lumen of oesophagus near anterior extremity. Nerve-ring in mid-region of oesophagus; deirids and excretory pore posterior to oesophagus.

Male. Holotype: total length 16.2; maximum width 0.69 ; buccal capsule 0.08 wide $\times 0.02$ deep; oesophagus 0.63 long; nerve-ring 0.28 , excretory pore 0.80 and deirids 0.89 from anterior end; spicules 1.47 long; gubernaculum 0.12 long. Paratypes: total length 17.6; maximum width 0.63-0.85 $(0.76, \mathrm{n}=11)$; buccal capsule $0.08-0.11(0.09, \mathrm{n}=11)$ wide $\times 0.02-0.03(0.028, \mathrm{n}=11)$ deep; oesophagus $0.60-0.70(0.64, \mathrm{n}=11)$ long; nerve-ring $0.26-0.34(0.28, \mathrm{n}=11)$, excretory pore 0.65-0.90 $(0.74, \mathrm{n}=11)$ and deirids $0.68-0.95(0.81, \mathrm{n}=11)$ from anterior end; spicules $1.45-1.70$ $(1.53, \mathrm{n}=11)$ long; gubernaculum 0.17-0.13 (0.09, $\mathrm{n}=10)$ long. Bursa without clear distinctions between ventral, lateral and dorsal lobes; dorsal lobe slightly longer than other lobes; pre-bursal ray (1) short, stout; ventro-ventral (2) and ventro-lateral (3) rays apposed, reaching margin of bursa; 
antero-lateral (4) and medio-lateral (5) rays apposed, reaching or almost reaching (4) margin of bursa; postero-lateral ray (6) divergent from other lateral rays, reaching margin of bursa; externolateral ray (8) arising from lateral trunk, reaching margin of bursa; dorsal ray broad at origin, lateral branchlets arising close to origin, short, each with 2 papillae; main trunk of dorsal ray elongate dividing near extremity into two short branchlets each with single papilla. Genital cone with large ventral projection bearing single terminal papilla (0); dorsal lip with paired conical projections (7) each bearing single terminal papilla; dorsal lobe of cone surrounded by array of projections. Spicules elongate alate; major ala arising immediately posterior to capitulum of spicule and extending almost to distal tip of spicule; spicules sinuous, ala arranged spirally around spicule; in distal region, smaller ala present on opposite side of spicule; spicule tips blunt.

Female. Allotype: length 18.0, maximum width 0.70 ; buccal capsule $0.09 \times 0.02$; oesophagus 0.69 long; nerve-ring 0.30 , excretory pore 0.79 and deirids 0.89 from anterior end; tail 0.27 long; vulva 0.39 from posterior end; vagina vera 1.35 long; sphincters and infundibula, 2.1 long; eggs absent. Paratypes: length not determined, maximum width 0.80-0.88 (0.83, $\mathrm{n}=10)$; buccal capsule 0.09-0.10 $(0.095, \mathrm{n}=10)$ wide $\times 0.020-0.040(0.030, \mathrm{n}=10)$ deep; oesophagus 0.62-0.68 (0.65, $\mathrm{n}=10)$ long; nerve-ring $0.23-0.32(0.28, \mathrm{n}=10)$, excretory pore $0.72-0.86(0.80, \mathrm{n}=10)$ and deirids 0.83-0.91 (0.86, $\mathrm{n}=6)$ from anterior end; tail short, conical, 0.16-0.29 (0.23, $\mathrm{n}=10)$ long; vulva immediately anterior to anus, $0.25-0.38(0.31, \mathrm{n}=10)$ from posterior end; vagina vera $1.33-1.50$ $(1.43, \mathrm{n}=10)$ long; sphincters and infundibula not differentiable, 1.65-2.30 (1.98, $\mathrm{n}=10)$ long; eggs absent.

\section{Remarks}

This species appears to differ from all congeners other than $K$. solitaria in possessing a buccal capsule with a lobed anterior margin and a genital cone with numerous papillae arranged in the shape of a horseshoe around the principal papillae. The features distinguishing $K$. solitaria from congeners have been discussed above. Kiluluma ceratotherii differs from $K$. solitaria in possessing a wider and more shallow buccal capsule, less prominent lips, more posteriorly placed denticles in the oesophageal lumen and differences in the length of the oesophagus. There are minor differences in the bursal rays with the postero-lateral ray (ray 6) reaching the margin of the bursa in $K$. ceratotherii but not in K. solitaria. The spicules differ in length with those of $K$. solitaria being $1.68-1.98 \mathrm{~mm}$ 
long and those of $K$. ceratotherii being $1.45-1.70 \mathrm{~mm}$ in length. While relatively few specimens of $K$. solitaria were available, the range in lengths in $K$. ceratotherii was based on 12 specimens, suggesting that the observed difference may be reliable.

It is possible that Thapar $(1924,1925)$ did not observe the lobed anterior margin of the buccal capsule in the species he described and the types examined are now so dark that it is not possible to confirm this character in most of them. Even so, the projection of the leaf crown elements and the range of spicule sizes would limit comparisons to K. pachyderma, K. macdonaldi and $K$. cylindrica. Both $K$. pachyderma and K. macdonaldi have spicule lengths (1.95 and $2.55 \mathrm{~mm}$ respectively) beyond the range of those of $K$. ceratotherii $(1.45-1.70$, mean $1.53 \mathrm{~mm})$. In addition, the spicules of $K$. pachyderma are more sinuous and the dorsal ray is quite different (Fig. 40), while in $K$. macdonaldi the lateral branches of the dorsal ray are much longer and more slender than in $K$. ceratotherii. $K$. ceratotherii also differs from $K$. cylindrica significantly in the structure of the dorsal ray. Consequently, there are valid grounds for considering the species described here to be new.

\section{Kiluluma sp.}

Material examined: $1 \hat{\jmath}, 1$ q, from large intestine of Ceratotherium simium, Western Plains Open Range Zoo, Dubbo, New South Wales, Australia.

Deposition of specimens: 1 , , BMNH 2012.11.14.18.

Deposition of DNA data: Genotype 3, GenBank accession No. JX982336.

\section{Description (Figs. 26-36)}

General. Body with prominent, widely-spaced annulations; numerous very fine annulations between more prominent annulations; cervical cuticle inflated; cephalic collar prominent; mouth opening surrounded by 6 prominent lips, 2 lateral amphids, 4 submedian bipartite papillae surmounted on conical elevations of cuticle. Internal leaf crown of 6 elements with recurved tips on inner surface of each lip; tips of leaf crown elements not projecting beyond lips. Buccal capsule thick-walled, circular in apical view, prominently lobed anteriorly in dorsal-ventral and lateral views. Oesophagus clavate without teeth in oesophageal funnel; denticles present in lumen of oesophagus near anterior 
extremity. Nerve-ring in mid-region of oesophagus; deirids and excretory pore posterior to oesophagus.

Male. Total length 10.3; maximum width 0.38 ; buccal capsule 0.090 wide $\times 0.55$ deep; oesophagus 0.52 long; nerve-ring 0.30 , excretory pore 0.65 and deirids 0.69 from anterior end. Bursa without clear distinctions between ventral, lateral and dorsal lobes; dorsal lobe slightly longer than other lobes; pre-bursal ray (1) short, stout; ventro-ventral (2) and ventro-lateral (3) rays apposed, reaching margin of bursa; antero-lateral (4) and medio-lateral (5) rays apposed, reaching margin of bursa; postero-lateral ray (6) divergent from other lateral rays, reaching margin of bursa; externo-lateral ray (8) arising from lateral trunk, reaching margin of bursa; dorsal ray broad at origin, lateral branches arising close to origin, short, each with 2 papillae; main trunk of dorsal ray elongate dividing near extremity into two short branchlets each with single papilla. Genital cone with large ventral projection bearing single terminal papilla (0); dorsal lip with paired conical projections (7) each bearing single terminal papilla; dorsal lobe of cone surrounded by array of projections. Spicules elongate alate; major ala arising immediately posterior to capitulum of spicule and extending almost to distal tip of spicule; spicules sinuous, ala arranged spirally around spicule; spicule tips blunt; spicules 2.03 long; gubernaculum sub-cordiform; additional cuticularisation present in walls of cloaca posterior to gubernaculum.

Female. Length not obtained, maximum width 0.85 ; buccal capsule 0.110 wide $\times 0.060$ deep; oesophagus 0.60 long; nerve-ring 0.032 , excretory pore 0.80 and deirids 0.93 from anterior end; tail short, conical, 0.22 long; vulva immediately anterior to anus, 0.30 from posterior end; vagina vera 1.90 long; sphincters and infundibula not differentiable, 1.30 long; eggs thin-shelled ellipsoidal, 0.08 $\times 0.05$.

\section{Remarks}

This species appears to be new as it also has a lobed anterior margin to the buccal capsule, but has a deeper buccal capsule and more prominent lips than either $K$. solitaria or $K$. ceratotherii. In addition, the tips of the leaf crown do not project as they do in K. solitaria of $K$. ceratotherii. In this respect, the species described here resembles $K$. rhinocerotis and $K$. africana, but differs from these species in the shape of the buccal capsule which is not lobed anteriorly in these two species. 
Although the description of the species is relatively complete and DNA sequence data are available, we have refrained from naming the species as only a single male and female were present and in order to describe them adequately, it was necessary to dissect them. In the future, if additional specimens become available which are identifiable on the basis of both morphological and molecular characteristics, then the species could be named.

\section{Discussion}

The present study of three species of Kiluluma has confirmed the opinion of previous authors (Taylor, 1925; Sandground, 1933; Knapp et al., 1997) that detailed redescriptions are needed of almost all species, preferably with associated DNA sequence data (Knapp et al. 1997). The current series of descriptions and redescription commences this process and provides a basis for ongoing studies as suitably preserved material becomes available.

The descriptions presented here permit comments to be made on several aspects of the morphology of the genus including the extra-bursal or pre-bursal ray, the gubernaculum and associated structures and the anatomy of the female genital system.

Kiluluma is distinguished in part by the possession of an extra bursal ray ventral to the pair of ventral rays normally found in the Strongylida. Thapar (1924) identified the additional ray as the pre-bursal ray. Sandground (1933) used the term pre-ventral ray and also correctly identified it as an elongation of the pre-bursal papillae of other strongylids. In the present description, the term prebursal ray has been used to indicate its homology with the pre-bursal papillae. This difficulty of nomenclature is overcome if the numerical system of identifying the bursal rays proposed by Chabaud et al. (1970) is utilised in which this ray is simply numbered as ray 1 . The system suggested by Chabaud et al. (1970) has been used mainly within the Trichostrongylina rather than within the Strongylina, but in this instance appears to have an advantage in identifying homologous features. Thapar (1924) also provided a confusing discussion of the externo-lateral ray, considering it, erroneously, to be an additional ray.

Thapar (1925) presented an extensive discussion on the cuticular structures of the cloaca, concluding that in Kiluluma an "accessory piece" rather than a typical gubernaculum exists. Although based on the examination of a limited series of species, current observations suggest that a typical gubernaculum exists dorsal to the spicule tips but that there are additional longitudinal sclerotisations of the cloacal wall posterior to the gubernaculum. In addition, the paired recurrent 
structures illustrated by Thapar $(1924,1925)$ in his descriptions appear to be simply sclerotisations of the lining of the cloaca between the spicules and the intestine as shown in Fig. 36 in Kiluluma sp. This aspect of the anatomy of the genus requires more detailed investigation but the current observations cast doubt on Thapar's (1925) conclusions.

Thapar (1925) also suggested that the female genital system differed in Kiluluma since there was no 'ovejector' and that the vagina simply divided into two 'horns' which led to the uteri. Lichtenfels (1980) described the ovejectors of strongyloids in some detail and the pattern exhibited in species of Kiluluma clearly belongs to the Type I or Y-shaped ovejectors identified by Lichtenfels (1980). Lichtenfels (1980) used as his principal example of the Type I ovejector that found in Cyathostomum labiatum (Looss, 1902) from equids and while discussing variation in Type II ovejectors in some detail, he did not consider the variation in Type I ovejectors in as much detail, other than by a series of illustrations (Lichtenfels, 1980, figures 7.3-7.7) and in the use of several characters in his key to genera. In the species examined here, the vestibule was distinguishable only by the division of the vagina vera into two separate ducts and the divisions of the sphincters and infundibula were not observable. In species such as $C$. labiatum, the various divisions are identifiable based on changes in the arrangement of the outer musculature. In the species of Kiluluma described here, the musculature was uniform in appearance, consisting of bundles of circular muscles extending from the vulva to the uterus, with the diameter of the muscle bundles diminishing anteriorly but with no change in their orientation thus preventing the measurement of these individual components. Lichtenfels (1980) presented schematic representations of similar ovejectors for Sauricola Chapin, 1924 from tortoises and Choniangium Henry \& Bauche, 1914 from elephants but subsequently Lichtenfels \& Stewart (1981) described and illustrated in greater detail the ovejectors of species of Chapiniella Yamaguti, 1961 from tortoises. The morphology of the female genital system of Kiluluma is similar to that found in species of Chapiniella and therefore warrants further investigation as it varies somewhat from the other Type I ovejectors described by Lichtenfels (1980). However, the current examination of only three species of Kiluluma is inadequate for generalisations at the generic level.

Chabaud (1957) in a review of the specific characters used to differentiate species of Murshidia Lane, 1914 and Quilonia Lane, 1914 from elephants and rhinoceroses commented on the potential systematic importance of the projections surrounding the genital cone (as described here in species of Kiluluma) and the sclerotised structures in the lining of the oesophagus. The illustrations of Thapar $(1924,1925)$ suggest that specialised cuticular structures may be present in the oesophagus of $K$. africana, $K$. solitaria, $K$. goodeyi, K. brevivaginata and $K$. cylindrica, although 
these were not described and were not visible in the type-specimens of $K$. africana examined. Their position in the oesophagus was useful in distinguishing $K$. solitaria from $K$. ceratotherii and may be useful as a character to distinguish other species.

Additional studies on the morphology of this genus are required before its systematic and phylogenetic relationships can be resolved. Lichtenfels (1980) placed the genus within its own tribe Kiluluminea in the Cyathostominae Nicoll, 1927 and in his proposed phylogeny (Lichtenfels, 1980, figure 7.53) aligned it with the tribes Murshidiinea and Quiloniinea, both from African mammals. Its precise relationships to the various tribes within the Cyathostominae however remain to be determined.

Acknowledgements We wish to thank Ben Bryant, Cheryl Sangster, Jan Hall and Karrie Rose for collecting the material and making it available for study, and to Eileen Harris for help in accessing the collection of type- and other specimens held in The Natural History Museum, London.

\section{References}

Campbell, A. J., Gasser, R. B., \& Chilton, N. B. (1995). Differences in a ribosomal DNA sequence of Strongylus species allows identification of single eggs. International Journal for Parasitology, 25, 359-365.

Chabaud, A. G. (1957). Revue critique des nematodes du genre Quilonia Lane, 1914 et du genre Murshidia Lane, 1914. Annales de Parasitologie Humaine et Comparée, 32, 98-131.

Chabaud, A. G., Puylaert, F., Bain, O., Petter, A. J., \& Durette-Desset, M-C. (1970). Remarques sur l'homologie entre les papilles cloacales des Rhabditides et les côtes dorsales des Strongylida. Comptes Rendus Hebdomadaire des Séances de l'Académie des Sciences, 271, 1771-1774.

Gasser, R. B. (2006). Molecular tools-advances, opportunities and prospects. Veterinary Parasitology, 136, 69-89.

Gasser, R. B., Hu, M., Chilton, N. B., Campbell, B. E., Jex, A. J., Otranto, D., Cafarchia, C., Beveridge, I., \& Zhu, X. (2006). Single-strand conformation polymorphism (SSCP) for the analysis of genetic variation. Nature Protocols, 1, 3121-3128. 
Hoste, H., Chilton, N. B., Gasser, R. B., \& Beveridge, I. (1995). Differences in the second internal transcribed spacer (ribosomal DNA) between five species of Trichostrongylus (Nematoda: Trichostrongylidae). International Journal for Parasitology, 25, 75-80.

Huelsenbeck, J. P., \& Ronquist, F. (2001). MrBayes: Bayesian inference of phylogenetic trees. Bioinformatics, 17, 754-755.

Jooste, R. (1990). A checklist of the helminth parasites of the large domestic and wild mammals of Zimbabwe. Transactions of the Zimbabwe Scientific Association, 64, 16-32.

Knapp, S. E., Krecek, R. C., Horak, I. G., \& Penzhorn, B. L. (1997). Helminths and arthropods of black and white rhinoceroses in southern Africa. Journal of Wildlife Diseases, 33, 492-502.

Lichtenfels, J. R. (1980). Keys to genera of the superfamily Strongyloidea. In: Anderson, R. C., Chabaud, A. G. \& Willmott, S. (Eds) CIH keys to the nematode parasites of vertebrates. No. 7. Farnham Royal: Commonwealth Agricultural Bureaux, pp. 1-41.

Lichtenfels, J. R., \& Stewart, T. B. (1981). Three new species of Chapiniella Yamaguti, 1961 (Nematoda: Strongyloidea) from tortoises. Proceedings of the Helminthological Society of Washington, 48, 137-147.

McLean, E. R., Kinsella, J. M., Chiyo, P., Obanda, V., Moss, C., \& Archie, E. A. (2012). Genetic identification of five strongyle nematode parasites in wild African elephants (Loxodonta africana). Journal of Wildlife Diseases, 48, 707-716.

Mönnig, H. O. (1927). Helminthological notes. $11^{\text {th }}$ and $12^{\text {th }}$ Report of the Director of Veterinary Education and Research, Department of Agriculture, Union of South Africa; Pretoria, 221-226.

Neveu-Lemaire, M. (1924). Les strongylidés du rhinoceros africain (Rhinoceros bicornis). Annales de Parasitologie Humaine et Comparée, 2, 121-151.

Penzhorn, B. L., Krecek, R. C., Horak, A. J., Verster, A. J. M., Walker, J. B., Boomker, J. D. F., Knapp, S. E., \& Quandt, S. K. F. (1994). Parasites of African rhinos: a documentation. In: Penzhorn, B.L. \& Kriek, N.P.J. (Eds) Proceedings of a symposium on rhinos as game ranch animals. South African Veterinary Association Wildlife Group, Onderstepoort; Republic of South Africa, pp. 168-175.

Posada, G., \& Crandall, K. A. (1998). Modeltest: testing the model of DNA substitution. Bioinformatics, 14, 817-818.

Ronquist, F., \& Huelsenbeck, J. P. (2003) MrBayes 3: Bayesian phylogenetic inference under mixed models. Bioinformatics, 19, 1572-1574. 
Round, M. C. (1968). Checklist of the helminth parasites of African mammals. Technical

Communication No. 38. Buckinghamshire: Commonwealth Agricultural Bureau, pp. 252.

Sandground, J. H. (1933). Two new helminths from Rhinoceros sondaicus. Journal of Parasitology, 19, 192-204.

Skrjabin, K. I. (1916). Parasitic trematodes and nematodes collected by the expedition of Prof. V. Dogiel and I. Sokolov in British East Africa. Scientific Reports of the zoological expedition to British East Africa and Uganda by Prof. V. Dogiel and I. Sokolov in 1914, 1(4), 1-157.

Taylor, E. L. (1925). The genus Kiluluma. Annals of Tropical Medicine and Parasitology, 19, $53-55$.

Thapar, G. S. (1924). On Kiluluma Skriabin, a genus of strongylid nematodes parasitic in the African rhinoceros. Journal of Helminthology, 2, 209-238.

Thapar, G. S. (1925). On some new members of the genus Kiluluma from the African rhinoceros. Journal of Helminthology, 3, 63-80.

Werle, E., Schneider, C., Renner, M., Volker, M., \& Fiehn, W. (1994). Convenient single-step, one tube purification of PCR products for direct sequencing. Nucleic Acids Research, 22, 4354-4355.

Yorke, W., \& Maplestone, P.A. (1926). The nematode parasites of vertebrates. London: Churchill \& Sons, pp. 536.

\section{Captions to figures:}

Fig. 1 Phylogenetic relationships of Kiluluma spp. (bold) based on ITS-2 sequence data determined herein, together with selected related reference sequences. Relationships were inferred based on analyses employing Bayesian Inference (BI) method. Nodal support is given as a posterior probability for BI. The scale-bar indicates distance. GenBank accession numbers are shown in parentheses.

Figs. 2-7 Kiluluma solitaria Thapar, 1924. 2. Anterior end, lateral view. 3. Cephalic extremity, lateral view, ventral aspect on left. 4. Cephalic extremity, ventral view. 5. Cephalic papilla. 6. Cephalic extremity, apical view. 7. Oesophagus, anterior extremity, ventral view showing denticles in lumen. Scale-bars: 2-5, 7, $0.1 \mathrm{~mm} . ; 6,0.01 \mathrm{~mm}$. 
Figs. 8-13 Kiluluma solitaria Thapar, 1924. 8. Bursa, apical view. 9. Bursa, lateral view. 10. Spicules, ventral view. 11. Gubernaculum, ventral view. 12. Terminal female genitalia, ventral view. 13. Female tail, lateral view. Scale-bars: $0.1 \mathrm{~mm}$.

Figs. 14-19 Kiluluma ceratotherii n. sp. 14. Anterior end, lateral view. 15. Cephalic extremity, ventral view. 16. Cephalic extremity, lateral view, ventral aspect on right. 17. Cephalic extremity, apical view. 18. Cephalic papilla. 19. Oesophagus, anterior extremity, ventral view showing denticles in lumen. Scale-bars: 14-17, 19, $0.1 \mathrm{~mm} . ; 18,0.01 \mathrm{~mm}$.

Figs. 20-25 Kiluluma ceratotherii n. sp. 20. Bursa, apical view. 21. Bursa, lateral view. 22. Spicules, ventral view. 23. Gubernaculum, ventral view. 24. Terminal female genitalia, ventral view. 25. Female tail, lateral view. Scale-bars: $0.1 \mathrm{~mm}$.

Figs. 26-33 Kiluluma sp. 26. Anterior end, lateral view. 27. Cephalic extremity, lateral view, ventral aspect on right. 28. Cephalic extremity, ventral view. 29. Cephalic extremity, apical view. 30. Cephalic papilla. 31. Bursa, apical view. 32. Terminal female genitalia, ventral view. 33. Female tail, lateral view. Scale-bars: 26-29, 31-33, $0.1 \mathrm{~mm} . ; 30,0.01 \mathrm{~mm}$.

Figs. 34-36 Kiluluma sp. 34. Spicules, ventral view. 35. Bursa, lateral view. 36. Posterior end of male, ventral view, showing cuticularised thickenings of cloacal walls.

Figs. 37-41 Dorsal rays of various species of Kiluluma drawn from type-specimens, drawn to same scale. 37. K. rhinocerotis. 38. K. solitaria. 39. K. macdonaldi. 40. K. africana. 41. K. pachyderma. Scale-bars: $0.1 \mathrm{~mm}$. 


\section{University Library}

\section{- M I N E R VA \\ A gateway to Melbourne's research publications}

Minerva Access is the Institutional Repository of The University of Melbourne

Author/s:

Beveridge, I;Jabbar, A

Title:

New species of Kiluluma Skrjabin, 1916 (Nematoda: Strongylida) from the white rhinoceros Ceratotherium simium (Burchell), with a redescription of K-solitaria Thapar, 1924

Date:

2013-06-01

\section{Citation:}

Beveridge, I. \& Jabbar, A. (2013). New species of Kiluluma Skrjabin, 1916 (Nematoda:

Strongylida) from the white rhinoceros Ceratotherium simium (Burchell), with a redescription of K-solitaria Thapar, 1924. SYSTEMATIC PARASITOLOGY, 85 (2), pp.131-145. https:// doi.org/10.1007/s11230-013-9417-8.

Persistent Link:

http://hdl.handle.net/11343/282867 